\title{
Prognostic role of long non-coding RNA TUG1 expression in various cancers: a meta-analysis
}

\author{
Yongping Zhou ${ }^{1}$, Yuxuan Lu ${ }^{2}$, Runmin $\mathrm{Li}^{2}$, Nana Yan ${ }^{3}$, Xiding $\mathrm{Li}^{4}$ and Tu Dai ${ }^{1}$ \\ ${ }^{1}$ Department of Hepatobiliary, Wuxi Second Hospital, Nanjing Medical University, Wuxi, China \\ ${ }^{2}$ School of Medicine, Tongji University, Shanghai, China \\ ${ }^{3}$ Department of Endocrinology, Hebei General Hospital, Shijiazhuang, China \\ ${ }^{4}$ Department of General Surgery, Wuxi Second Hospital, Nanjing Medical University, Wuxi, China \\ Correspondence to: Tu Dai, email: 810704041@qq.com \\ Xiding Li, email: lixiding007@163.com
}

Keywords: long non-coding RNA TUG1, cancer, prognostic

Received: May 10, 2017 Accepted: July 26, $2017 \quad$ Published: August 08, 2017

Copyright: Zhou et al. This is an open-access article distributed under the terms of the Creative Commons Attribution License 3.0 (CC BY $3.0)$, which permits unrestricted use, distribution, and reproduction in any medium, provided the original author and source are credited.

\section{ABSTRACT}

Several studies were conducted to explore the prognostic role of long noncoding RNA taurine upregulated gene 1 (IncRNA TUG1) expression in various cancers, with contradictory. This study aims to summarize the prognostic role of IncRNA TUG1 expression in various cancers. Embase, PubMed and Cochrane Library were completely retrieved. The cohort studies focusing on the prognostic role of IncRNA TUG1 expression in various cancers were eligible. The endpoints were overall survival (OS) and clinicopathological parameters. 9 studies involving a total of 1,078 patients were identified. The results showed that high IncRNA TUG1 expression was obviously associated with worse OS when compared to the Iow IncRNA TUG1 expression $\left(H R=1.37,95 \%\right.$ CI $\left.=1.07-1.76, P=0.01 ; I^{2}=85 \%\right)$. However, No distinct relationship was observed between the IncRNA TUG1 expression and age $(O R=0.99$, $95 \% \mathrm{CI}=0.76-1.28, P=0.92 ; \mathrm{I} 2=4 \%)$, gender $(\mathrm{OR}=0.92,95 \% \mathrm{CI}=0.70-1.22$, $\left.P=0.57 ; \mathrm{I}^{2}=0 \%\right)$, diameter $\left(\mathrm{OR}=0.83,95 \% \mathrm{CI}=0.34-2.01, P=0.67 ; \mathrm{I}^{2}=85 \%\right)$, smoking (OR $\left.=1.09,95 \% \mathrm{CI}=0.37-3.21, P=0.87 ; \mathrm{I}^{2}=73 \%\right)$, TNM stage $(\mathrm{OR}=0.60$, $\left.95 \% \mathrm{CI}=0.25-1.43, P=0.25 ; \mathrm{I}^{2}=86 \%\right)$ and lymph node metastasis ( $\mathrm{OR}=1.07$, $95 \% \mathrm{CI}=0.47-2.45, P=0.87 ; \mathrm{I}^{2}=86 \%$ ). In conclusion, it was revealed that high IncRNA TUG1 expression is an unfavorable predictor of OS in patients with cancers, and IncRNA TUG1 expression is a promising prognostic biomarker for various cancers.

\section{INTRODUCTION}

Cancer has become a major public health problem heavily threatening human health and life $[1,2]$. Early diagnosis and treatment are critical for the prognosis of cancers [3]. Recently, great progress of diagnosis and treatment in various cancers has been made, however, the prognosis of a large number of individuals remains disappointing [4-7]. Besides, many researchers are focusing on the new biomarkers to elevate the efficacy of diagnosis, prognosis, and treatment of cancers $[8,9]$. Nevertheless, the exact mechanism of biomarkers in carcinogenesis is still unclear [10]. Therefore, more and more attention was paid to identify specific biomarkers for prognosis of patients with cancers [11-13].
With the development of technology, long noncoding RNAs (lncRNAs) attract more and more attention of cancer researchers [14-17]. LncRNAs were more than 200 nucleotides in length without the protein-coding function [17]. Recently, the critical roles of some lncRNAs have been confirmed in some tumors, such as gastric cancer [18], lung cancer [19, 20], ovarian cancer [21], liver cancer [22] and so on. However, the detailed information of the most lncRNAs in cancers remains unclear.

LncRNA taurine upregulated gene 1 (nncRNA TUG1) was initially detected in mouse retinal cells, and the expression level could be unregulated with addition of taurine [23]. Recently, a great number of studies indicate that lncRNA TUG1 might participate in progression of a variety of cancers, including non-small cell lung 
cancer [24], colorectal cancer [25], esophageal squamous cell carcinoma [26], gastric cancer [18] and hepatocellular carcinoma [27] as well as osteosarcoma [28]. Thus to date, the true function of IncRNA TUG1 in cancers was controversial. Iliev et al. reported that overexpression of lncRNA TUG1 might predict poor prognosis in high-grade muscle-invasive bladder cancer [29], similar results were reported by Wang et al. in clear cell renal cell carcinoma [30]. On the contrary, Zhang et al. declared that the lower expression of lncRNA TUG1 was related to higher TNM stage, tumor size and poorer overall survival [18]. In light and consideration of these controversial results, this metaanalysis was performed to explore the prognostic and clinical-pathological significance of lncRNA TUG1 in various cancers.

\section{MATERIALS AND METHODS}

\section{Literature search strategy}

PubMed, Embase and the Cochrane Library database were comprehensively searched up to May 24, 2017. The search strategy was "(((long non-coding RNA) OR lncRNA)) AND ((taurine-upregulated gene 1) OR TUG1)". All the retrieved papers and their reference lists were carefully checked. The obviously irrelevant articles were directly excluded by scanning the titles or abstracts. The remaining papers were then reviewed comprehensively by carefully reading the full text.

\section{Inclusion criteria}

The studies meeting all the following criteria would be included: 1) prospective or retrospective studies; 2) focusing on the role of IncRNA TUG1 expression on the prognosis in all cancers; 3 ) reporting enough data to get the hazard ratio (HR) for prognostic outcomes, along with their $95 \%$ confidence intervals (CIs) or $P$ values; 4 ) studies published in English.

\section{Exclusion criteria}

The exclusion criteria were as follows: 1) letters, reviews, case reports and expert opinions; 2) without enough data to obtain the HR; 3) not focusing on the prognostic role of IncRNA TUG1 expression on the prognosis in various cancers; 4) not published in English; 5) duplicate publications; 6) reporting the overlapping data.

\section{Data extraction}

All manuscripts were independently reviewed by two investigators. For each included studies, the following data was carefully abstracted: first name of the first author, year of publication, country of the study, ethnicity, the number of patients, percentage of males, tumor type, survival outcomes and analysis model. The HRs of prognostic outcomes obtained directly or indirectly from published articles were integrated in the meta-analysis according to the study conducted by Tierney et al. [31]. The HR assessed with multivariate analysis was abstracted when the multivariate analysis and univariate analysis were both applied in the study. The Newcastle-Ottawa Scale (NOS) was used to assess the quality of included studies. And the study with NOS score $\geq 6$ was considered to be of high quality. Any other disputes were discussed with the third investigator.

\section{Statistical analysis}

Meta-analysis was carried out by Review Manager Version 5.3 software. The prognosis outcomes were assessed using the HR, along with the corresponding 95\% CI or $P$ values. The prognosis outcomes mainly contained the overall survival (OS) and some clinical parameters. The Cochran's $Q$ test and Higgins $\mathrm{I}^{2}$ were used to assess the heterogeneity among included studies. The heterogeneity should be considered if $\mathrm{I}^{2}>50 \%$, and the random-effect model was applied; if not, the fixedeffect model was applied. In additions, the funnel plot was conducted to evaluate publication bias by Review Manager Version 5.3 software. The difference was considered to be significant when $P$ value less than 0.05 .

\section{RESULTS}

\section{Literature search}

The meta-analysis was conducted according to PRISMA statement (Supplementary Table 1). As shown in Figure 1, 95 articles were initially identified from the PubMed, Embase and Cochrane library. Among the identified articles, 31 articles were excluded for duplications. For the rest articles, 40 articles were excluded by scanning the abstracts or titles. Regarding the rest articles, all of them were analyzed by carefully reading the full text. 7 articles were abandoned because the style of them was not cohort study but also letter, case report or review. Besides, 8 articles were excluded for not reporting the detailed information of the HR of OS. At last, 9 studies involving 1,078 were finally included into the current meta-analysis [18, 24-26, 28-30, 32, 33].

\section{Characteristics of included studies}

The details of the included studies were presented in Table 1. A total of 9 studies involving 1,078 patients were analyzed in the meta-analysis [18, 24-26, 28-30, 32, 33]. Regarding cancer type, the included studies focused on the non-small cell lung cancer (NSCLC) [24, 32], small cell lung cancer (SCLC) [33], bladder cancer [29], gastric 
Table 1: The main information of included studies in the meta-analysis

\begin{tabular}{|c|c|c|c|c|c|c|c|c|c|c|}
\hline \multirow{2}{*}{ Study } & \multirow{2}{*}{ Year } & \multirow{2}{*}{ Cancer type } & \multirow{2}{*}{$\begin{array}{c}\text { Total } \\
\text { number }\end{array}$} & Tumor stage & Follow-up & \multirow{2}{*}{ Therapy } & \multirow{2}{*}{$\frac{\text { Detection }}{\text { method }}$} & \multirow{2}{*}{$\frac{\text { Clinical }}{\text { outcomes }}$} & \multirow{2}{*}{ Analysis } & \multirow{2}{*}{ NOS } \\
\hline & & & & I-II/III-IV & (months) & & & & & \\
\hline Zhang et al. [24] & 2014 & NSCLC & 192 & $129 / 63$ & $>60$ & NA & qRT-PCR & OS, & M & 6 \\
\hline Iliev et al. [29] & 2016 & Bladder cancer & 47 & NA & $42 \pm 5$ & Surgery & qRT-PCR & OS & $\mathrm{U}$ & 7 \\
\hline Jiang et al. [26] & 2016 & ESCC & 218 & $96 / 114$ & $17(12-72)$ & Chemotherapy & qRT-PCR & OS & M & 7 \\
\hline Lin et al. [32] & 2016 & NSCLC & 89 & $69 / 20$ & $>80$ & NA & qRT-PCR & OS & $\mathrm{U}$ & 6 \\
\hline Ma et al. [28] & 2016 & Osteosarcoma & 76 & $64 / 12$ & $44(3-60)$ & Surgery & qRT-PCR & OS,PFS & M & 7 \\
\hline Niu et al. [33] & 2017 & SCLC & 33 & $16 / 17$ & NA & NA & qRT-PCR & OS & $\mathrm{U}$ & 7 \\
\hline Sun et al. [25] & 2016 & Colorectal cancer & 120 & NA & $36(2-60)$ & Surgery & qRT-PCR & OS & U & 7 \\
\hline Wang et al. [30] & 2017 & CCRCC & 203 & $119 / 84$ & $>70$ & Surgery & qRT-PCR & OS & M & 6 \\
\hline Zhang et al. [18] & 2016 & Gastric cancer & 100 & $57 / 43$ & $>60$ & Surgery & qRT-PCR & OS & M & 7 \\
\hline
\end{tabular}

OS = overall survival; NSCLC = non-small cell lung cancer; $\mathrm{ESCC}=$ esophageal squamous cell carcinoma; SCLC = small cell lung cancer; $\mathrm{CCRCC}=$ clear cell renal cell carcinoma; NA = not available; Multivariate: multivariate analysis; Univariate: univariate analysis; PFS = progression free survival; NOS = Newcastle-Ottawa Scale.

cancer [18], esophageal squamous cell carcinoma (ESCC) [26], osteosarcoma [28] and colorectal cancer [25] as well as clear cell renal cell carcinoma (CCRCC) [30]. As for the sample size, the number of included patients varied a lot, from 33 to 218. In additions, 7 studies reported the tumor stage of the included patients $[18,24,26,28$, $30,32,33]$ and 8 studies reported the detailed follow up time $[18,24-26,28-30,32]$. As for the therapy, patients enrolled in 5 studies received surgery [18, 25, 28-30] and in 1 study received chemotherapy [26], however, 3 studies

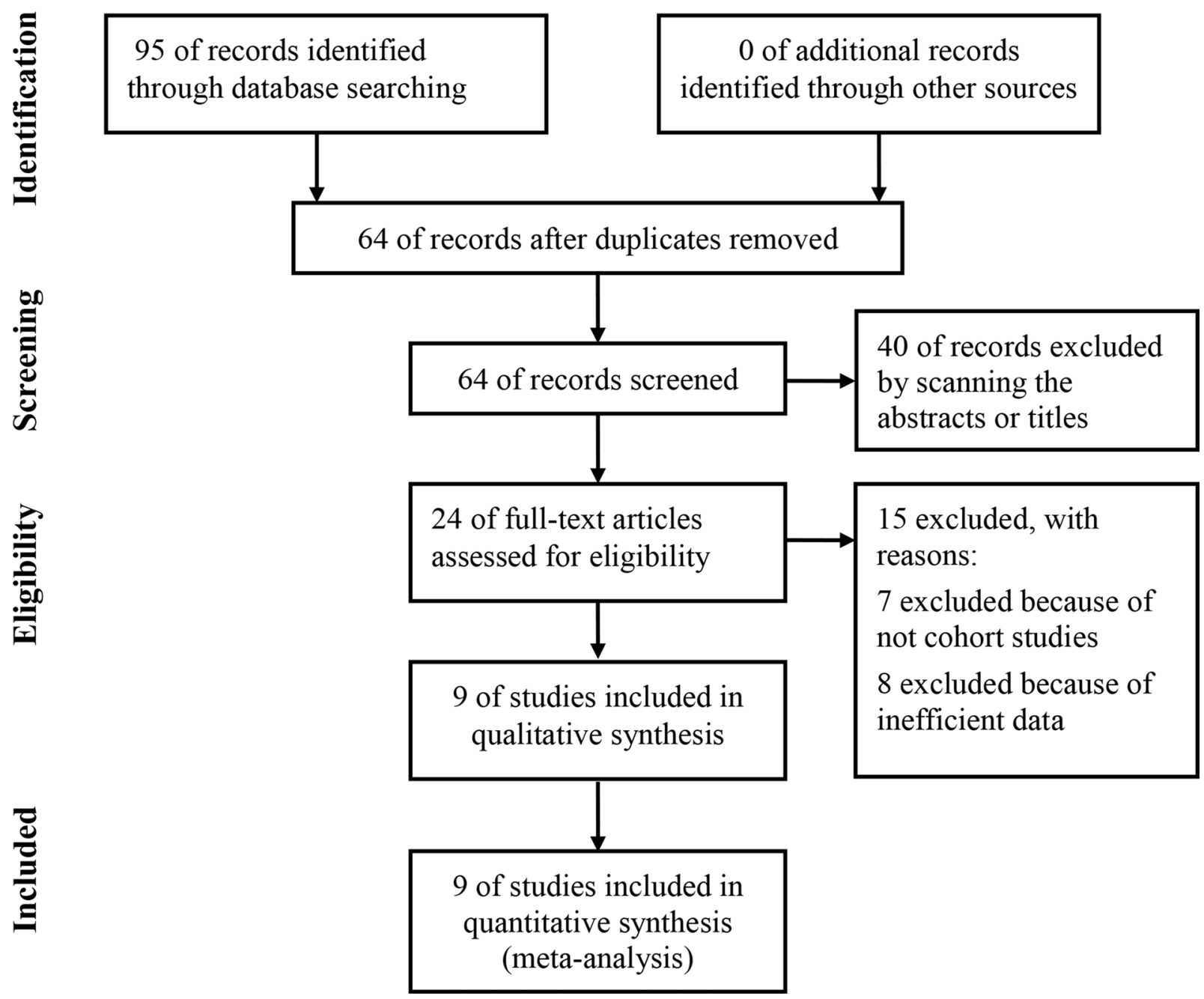

Figure 1: Flow diagram of study selection process. 
didn't report the detailed information of the therapies $[24,32,33]$. All the included studies use qRT-PCR to detect the expression of LncRNA TUG1 [18, 24-26, 28-30, 32, 33]. As for the clinical outcomes reported in studies, all the included studies reported the OS [18, 24-26, 28-30, 32, 33], however, only 1 study presented the PFS [28]. In additions, OS in 5 studies were assessed with multivariate analysis $[18,24,26,28,30]$ and 4 studies were assessed with univariate analysis [25, 29, 32, 33]. Regarding quality of included studies, the NOS of all the included studies were more than or equal to 6 , which indicated that all the included studies had relatively high quality [18, 24-26, 28-30, 32, 33].

\section{Association between the IncRNA TUG1 expression and $\mathrm{OS}$}

All the included studies reported the information of OS. As shown in Figure 2, the random-effect model was used for the significant heterogeneity $\left(\mathrm{I}^{2}=85 \%\right)$. There was an obvious relationship between the lncRNA TUG1 expression and the OS, and the results presented that patients with low lncRNA TUG1 expression have longer OS when compared to the patients with high lncRNA TUG1 $(\mathrm{HR}=1.37,95 \% \mathrm{CI}=1.07-1.76$, $P=0.01)$. The details of the funnel plot were presented in Figure 3.

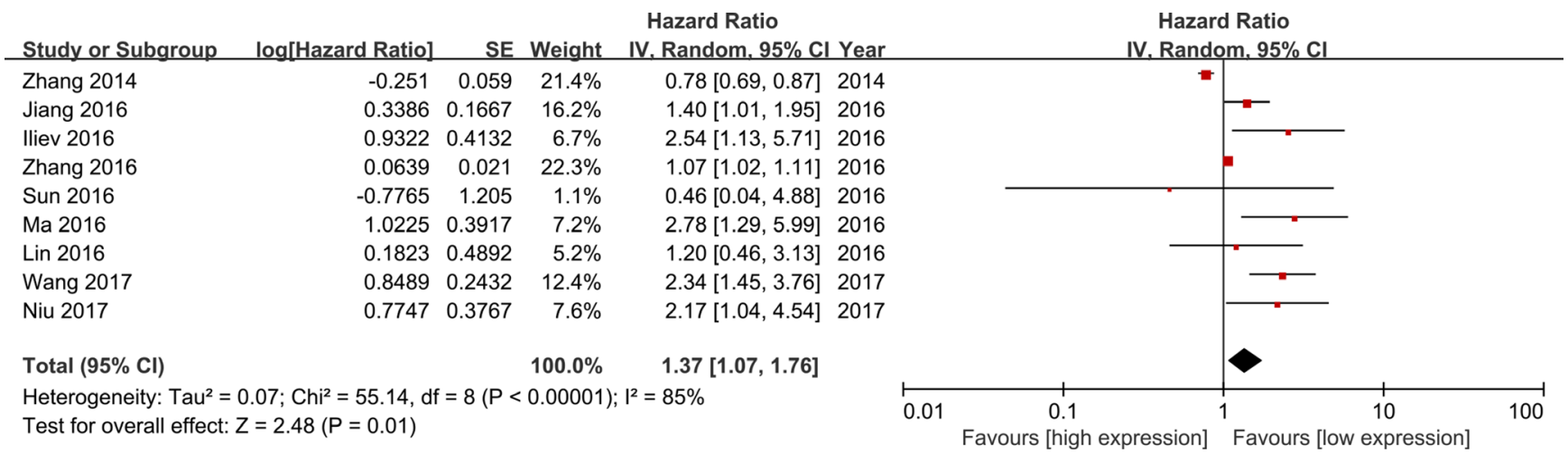

Figure 2: Meta-analysis of overall survival.

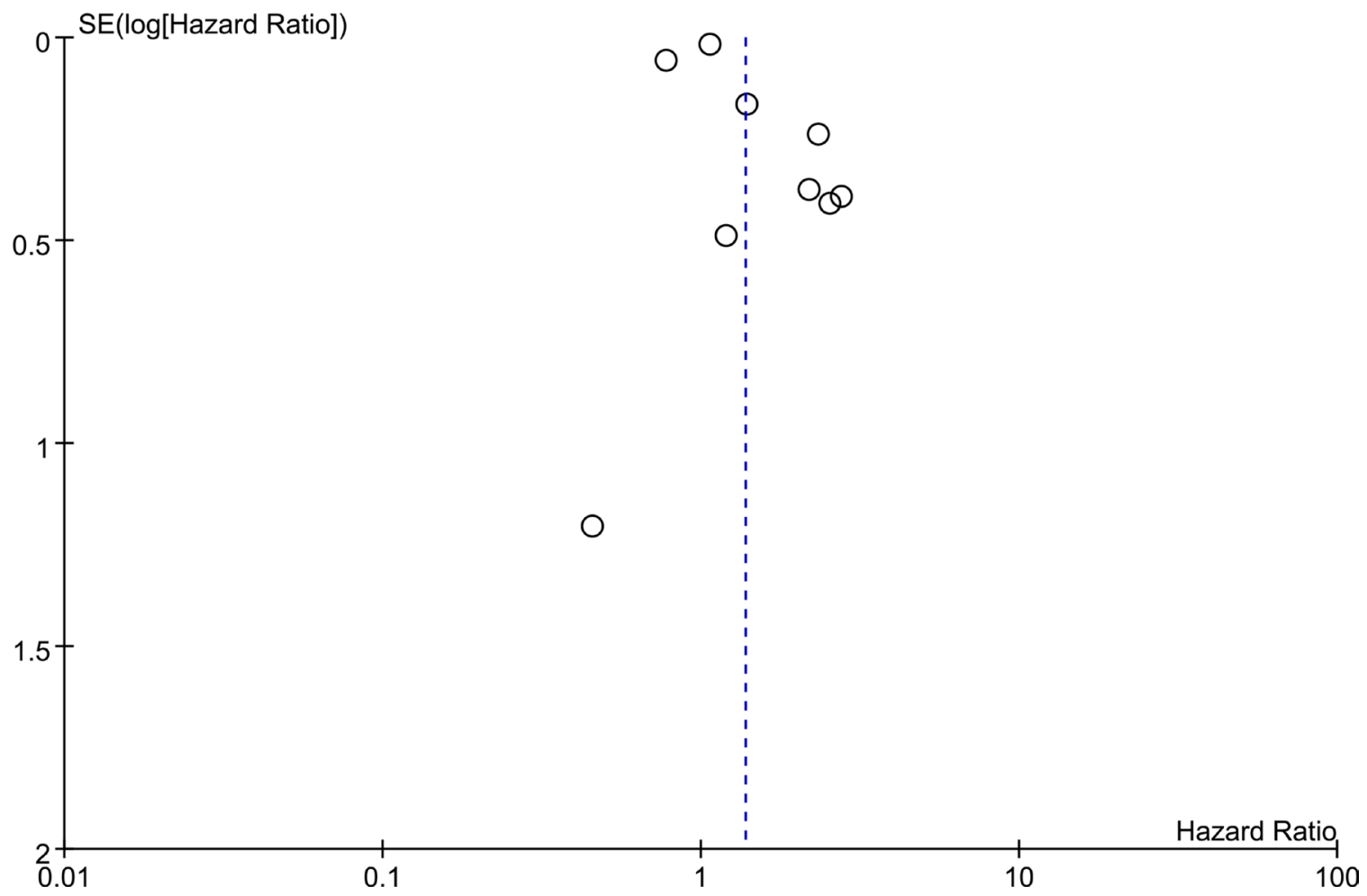

Figure 3: Funnel plot of overall survival. 


\section{Association between IncRNA TUG1 expression and clinicopathological parameters}

As shown in Figure 4, the meta-analysis was conducted to explore the association between IncRNA
TUG1 expression and clinicopathological parameters. No distinct relationship was observed between the lncRNA TUG1 expression and age $(\mathrm{OR}=0.99,95 \%$ $\left.\mathrm{CI}=0.76-1.28, P=0.92 ; \mathrm{I}^{2}=4 \%\right)$, gender $(\mathrm{OR}=0.92$, $95 \%$ CI $=0.70-1.22, P=0.57 ; \mathrm{I}^{2}=0 \%$ ), diameter

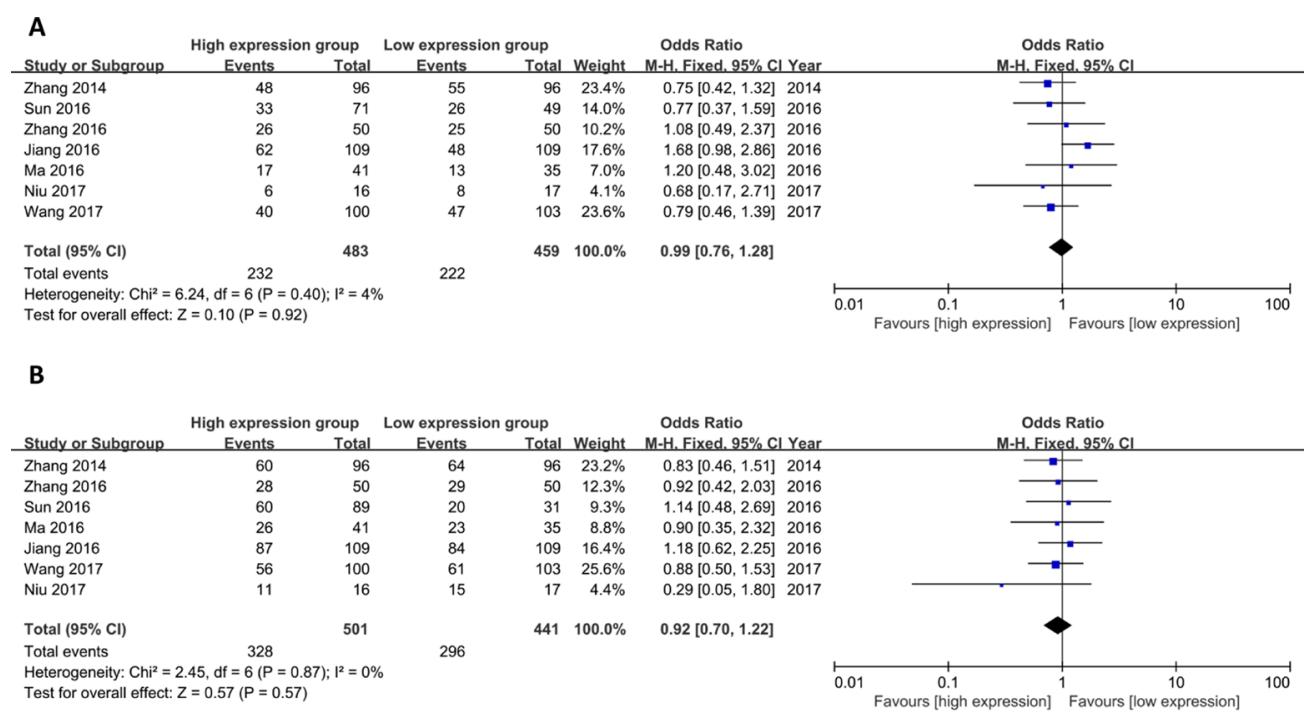

C

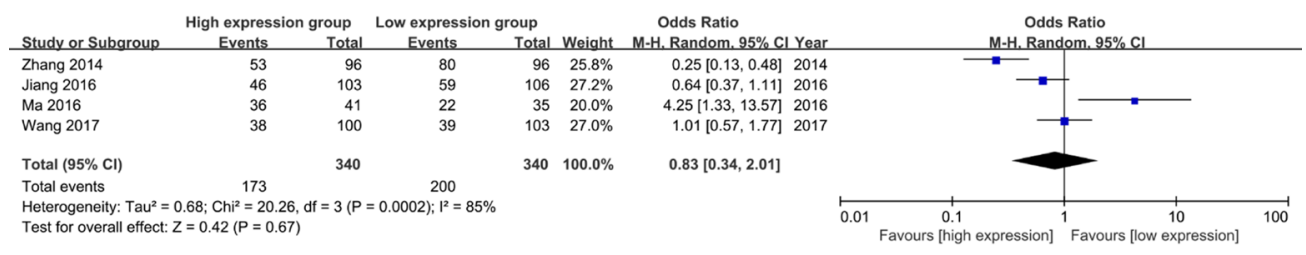

。

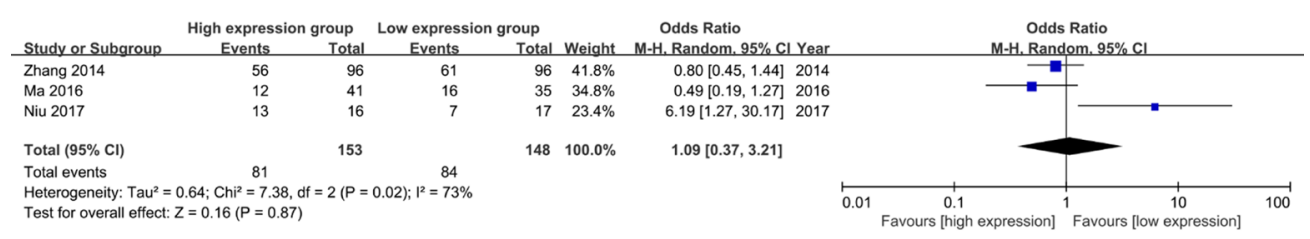

E

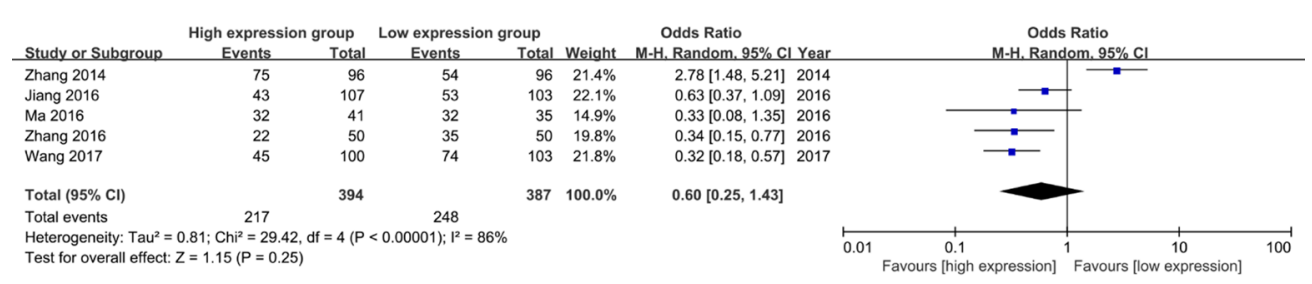

,

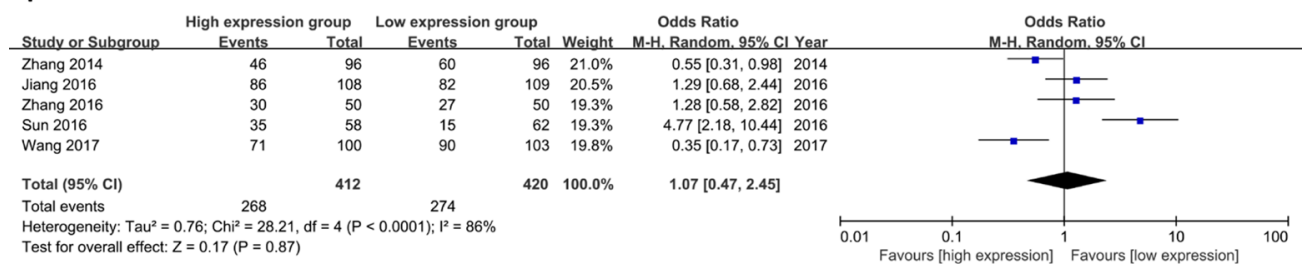

Figure 4: Meta-analysis of clinicopathological parameters (A age; B gender; C diameter; $\mathbf{D}$ smoking; $\mathbf{E}$ TNM stage; $\mathbf{F}$ lymph node metastasis). 
$\left(\mathrm{OR}=0.83,95 \% \mathrm{CI}=0.34-2.01, P=0.67 ; \mathrm{I}^{2}=85 \%\right)$, smoking $\left(\mathrm{OR}=1.09,95 \% \mathrm{CI}=0.37-3.21, P=0.87 ; \mathrm{I}^{2}\right.$ $=73 \%)$, TNM stage $(\mathrm{OR}=0.60,95 \% \mathrm{CI}=0.25-1.43, P=$ $\left.0.25 ; \mathrm{I}^{2}=86 \%\right)$ and lymph node metastasis $(\mathrm{OR}=1.07,95 \%$ $\mathrm{CI}=0.47-2.45, P=0.87 ; \mathrm{I}^{2}=86 \%$ ). The details of the funnel plots were presented in Figure 5.

\section{DISCUSSION}

With the development of technology, more and more attention was paid to the non-coding RNA $[14,34,35]$. LncRNAs were a class of endogenous RNAs without the protein-coding function, which range from 200 nucleotides to $\sim 100$ kilobases (kb) [36, 37]. Recently, increasing evidences have presented that lncRNAs were involved in the occurrence and progress of several disease, including cancers [37], liver disease [38], Parkinson's disease [39], and especially various cancers [18, 24, 25, $28,30,33,40]$. The lncRNAs might promote or prevent the tumorigenesis and development as oncogenes or tumor suppressor, respectively $[33,41]$.

LncRNA TUG1 was initially observed in mouse retinal cells with the addition of taurine. Increasing evidences have presented that LncRNA TUG1 might play
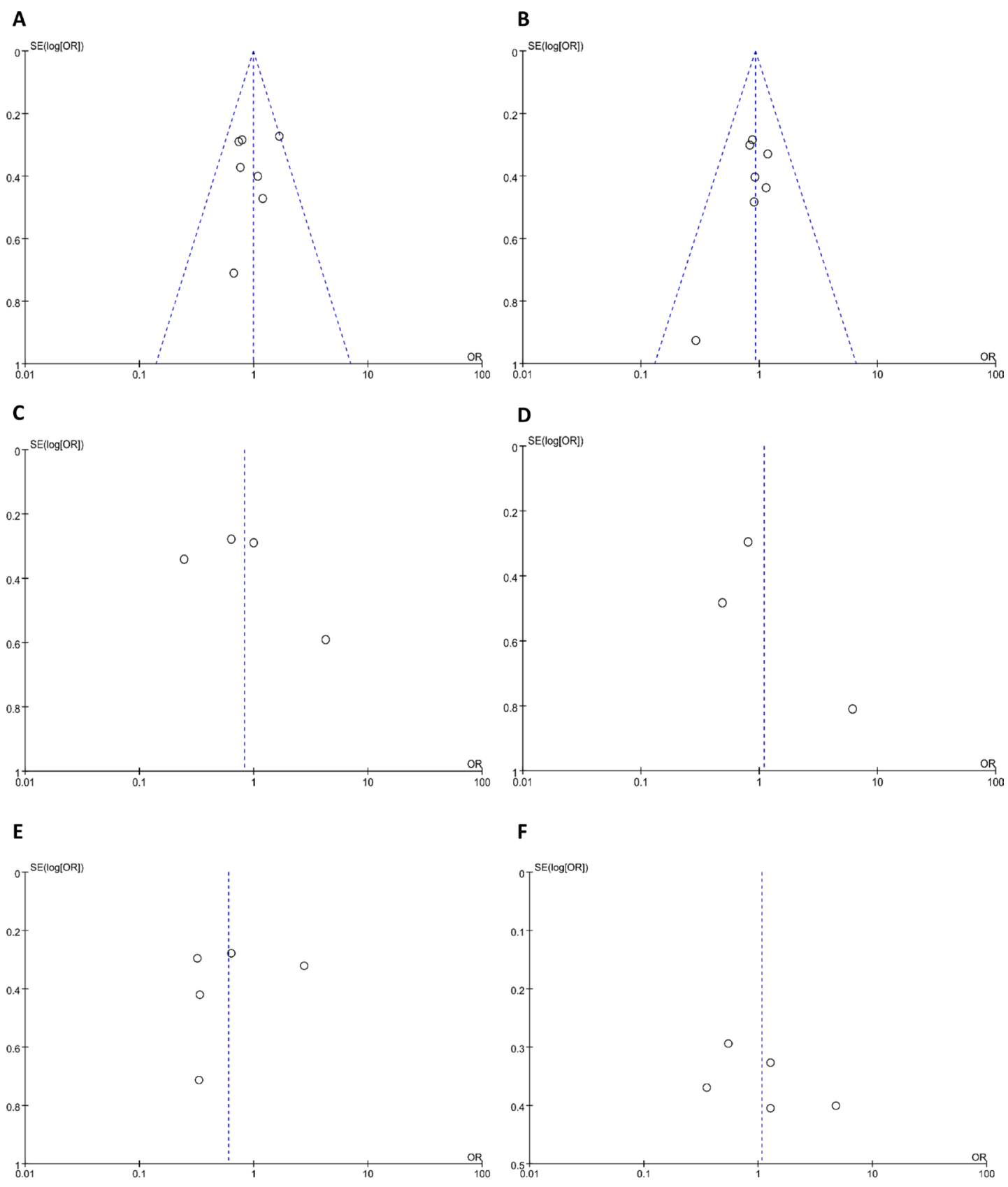

Figure 5: Funnel plot of clinicopathological parameters (A age; B gender; $\mathbf{C}$ diameter; $\mathbf{D}$ smoking; $\mathbf{E}$ TNM stage; $\mathbf{F}$ lymph node metastasis). 
an important role in the tumorigenesis and development of cancers. However, the potential mechanism still remains unclear. Ma et al. declared that long non-coding RNA TUG1 might promote cell proliferation and metastasis by negatively regulating miR-300 [42]. LncRNA TUG1 also might be involved in the regulation the expression of miR-335-5p in osteosarcoma cells [43]. Similarly, Cai et al. reported that IncRNA TUG1 regulated bloodtumor barrier permeability by targeting miR-144 [44]. Overexpression of IncRNA TUG1 promoted cervical cancer cell proliferation and migration via the progression of epithelial-mesenchymal transition [45]. Meanwhile, Niu et al. declared that lncRNA TUG1 was involved in cell growth and chemoresistance of small cell lung cancer by regulating LIMK2b via EZH2 [33]. In ovarian cancer, Kuang et al. discovered that lncRNA TUG1 might regulate cancer proliferation and metastasis via altering epithelialmesenchymal transition [41]. Moreover, Liu et al. declared that lncRNA TUG1 could induce apoptosis by targeting ZEB2 mediated by miR-142 through the inactivation of $\mathrm{Wnt} / \beta$-catenin pathway in bladder cancer [46].

In recent years, numerous studies discovered that LncRNA TUG1 expression was positively associated with prognostic outcomes in cancer patients, however, the results was controversial [29, 30, 32, 33].

In the current study, the results presented that high lncRNA TUG1 expression was an unfavorable prognostic factor in patients with cancers. Besides, no correlation between the IncRNA TUG1 expression and other clinicopathological parameters was observed, including age, gender, smoking, TNM stage, lymph node metastasis and diameter. Regarding PFS, only one study reported the relationship between the PFS and IncRNA TUG1 expression, and the results also indicated that high lncRNA TUG1 expression was an unfavorable prognostic factor. In conclusion, lncRNA TUG1 expression might play an important role in the prognosis of cancers and high lncRNA TUG1 expression might be an unfavorable prognostic factor. To the best of our knowledge, this study was the first meta-analysis to explore the relationship between the lncRNA TUG1 expression and prognosis of patients in cancers. And the results could encourage more researchers pay attention to the prognostic role of lncRNA TUG1 in cancers and further to explore the underlying mechanisms.

Some limitations should be considered of the current study. Firstly, the sample size of all the included studies was relatively small, which might reduce the reliability of the conclusion. Secondly, moderate heterogeneity was observed in some analyses including OS, TNM stage, smoking, and so on, which might influence the convincing of the results. Thirdly, this meta-analysis was only performed to explore the association between the lncRNA TUG1 expression and prognosis of patients in various cancers. No further analysis concerning the association between the lncRNA TUG1 expression and specific cancer was conducted for the limited included studies.
In conclusion, high lncRNA TUG1 expression is an unfavorable predictor of OS in various cancers, and lncRNA TUG1 expression is a promising prognostic biomarker for cancers.

\section{Author contributions}

Study concepts and design: Dai T, Li X; Literature search: Zhou Y; Data extraction: Zhou Y, Yan N, Lu Y; Data analysis: Li R, Zhou Y; Manuscript preparation and revision: Dai T, Zhou Y. All authors have participated sufficiently in the study and approved the final version.

\section{CONFLICTS OF INTEREST}

The authors declare that they have no conflicts of interest.

\section{FINANCIAL SUPPORT}

None.

\section{REFERENCES}

1. Chen W, Zheng R, Baade PD, Zhang S, Zeng H, Bray F, Jemal A, Yu XQ, He J. Cancer statistics in China, 2015. CA Cancer J Clin. 2016; 66:115-32. https://doi.org/10.3322/caac.21338.

2. Siegel RL, Miller KD, Jemal A. Cancer statistics, 2016. CA Cancer J Clin. 2016; 66:7-30. https://doi.org/10.3322/ caac. 21332.

3. Ledford H. Cancer studies clash over mechanisms of malignancy. Nature. 2015; 528:317. https://doi. org/10.1038/528317a.

4. Topalian SL, Hodi FS, Brahmer JR, Gettinger SN, Smith DC, McDermott DF, Powderly JD, Carvajal RD, Sosman JA, Atkins MB, Leming PD, Spigel DR, Antonia SJ, et al. Safety, activity, and immune correlates of anti-PD-1 antibody in cancer. N Engl J Med. 2012; 366:2443-54. https://doi.org/10.1056/NEJMoa1200690.

5. Huang J, Zhao Y, Xu Y, Zhu Y, Huang J, Liu Y, Zhao L, Li Z, Liu H, Wang QL, Qi X. Comparative effectiveness and safety between oxaliplatin-based and cisplatin-based therapy in advanced gastric cancer: A meta-analysis of randomized controlled trials. Oncotarget. 2016; 7:3482431. https://doi.org/10.18632/oncotarget.9189.

6. Zhao Y, Wang H, Shi Y, Cai S, Wu T, Yan G, Cheng S, Cui K, Xi Y, Qi X, Zhang J, Ma W. Comparative effectiveness of combined therapy inhibiting EGFR and VEGF pathways in patients with advanced non-small-cell lung cancer: a meta-analysis of 16 phase II/III randomized trials. Oncotarget. 2017; 8:7014-24. https://doi.org/10.18632/ oncotarget.12294.

7. Zheng M, Zhu Z, Zhao Y, Yao D, Wu M, Sun G. Oridonin promotes G2/M arrest in A549 cells by facilitating ATM 
activation. Mol Med Rep. 2017; 15:375-79. https://doi. org/10.3892/mmr.2016.6008.

8. Wang J, Zhao Y, Qi R, Zhu X, Huang C, Cheng S, Wang S, Qi X. Prognostic role of podocalyxin-like protein expression in various cancers: A systematic review and meta-analysis. Oncotarget. 2016; 8:52457-524. https://doi. org/10.18632/oncotarget.14199.

9. Zhao Y, Si G, Zhu F, Hui J, Cai S, Huang C, Cheng S, Fathy AH, Xiang Y, Li J. Prognostic role of platelet to lymphocyte ratio in hepatocellular carcinoma: a systematic review and meta-analysis. Oncotarget. 2017; 8:22854-22862. https:// doi.org/10.18632/oncotarget.15281.

10. Tang J, Jiang R, Deng L, Zhang X, Wang K, Sun B. Circulation long non-coding RNAs act as biomarkers for predicting tumorigenesis and metastasis in hepatocellular carcinoma. Oncotarget. 2015; 6:4505-15. https://doi. org/10.18632/oncotarget.2934.

11. Adeola HA, Blackburn JM, Rebbeck TR, Zerbini LF. Emerging proteomics biomarkers and prostate cancer burden in Africa. Oncotarget. 2017; 8:37991-38007. https:// doi.org/10.18632/oncotarget.16568.

12. Eichmuller SB, Osen W, Mandelboim O, Seliger B. Immune Modulatory microRNAs Involved in Tumor Attack and Tumor Immune Escape. J Natl Cancer Inst. 2017; 109. https://doi.org/10.1093/jnci/djx034.

13. Hou X, Wen J, Ren Z, Zhang G. Non-coding RNAs: new biomarkers and therapeutic targets for esophageal cancer. Oncotarget. 2017; 8:43571-43578. https://doi.org/10.18632/ oncotarget. 16721.

14. Adams BD, Parsons C, Walker L, Zhang WC, Slack FJ. Targeting noncoding RNAs in disease. J Clin Invest. 2017; 127:761-71. https://doi.org/10.1172/jci84424.

15. Ayers D, Vandesompele J. Influence of microRNAs and Long Non-Coding RNAs in Cancer Chemoresistance. Genes (Basel). 2017; 8. https://doi.org/10.3390/ genes 8030095 .

16. Luo P, Liu XF, Wang YC, Li ND, Liao SJ, Yu MX, Liang $\mathrm{CZ}, \mathrm{Tu}$ JC. Prognostic value of abnormally expressed lncRNAs in ovarian carcinoma: a systematic review and meta-analysis. Oncotarget. 2017; 8:23927-23936. https:// doi.org/10.18632/oncotarget.14760.

17. Wu T, Du Y. LncRNAs: From Basic Research to Medical Application. Int J Biol Sci. 2017; 13:295-307. https://doi. org/10.7150/ijbs.16968.

18. Zhang E, He X, Yin D, Han L, Qiu M, Xu T, Xia R, Xu $\mathrm{L}$, Yin R, De W. Increased expression of long noncoding RNA TUG1 predicts a poor prognosis of gastric cancer and regulates cell proliferation by epigenetically silencing of p57. Cell Death Dis. 2016; 7:e2109. https://doi.org/10.1038/ cddis.2015.356.

19. Huang C, Qin Y, Liu H, Liang N, Chen Y, Ma D, Han $\mathrm{Z}, \mathrm{Xu} \mathrm{X}$, Zhou X, He J, Li S. Downregulation of a novel long noncoding RNA TRPM2-AS promotes apoptosis in non-small cell lung cancer. Tumour
Biol. 2017; 39:1010428317691191. https://doi. org/10.1177/1010428317691191.

20. Tian H, Zhou C, Yang J, Li J, Gong Z. Long and short noncoding RNAs in lung cancer precision medicine: Opportunities and challenges. Tumour Biol. 2017; 39:1010428317697578. https://doi. org/10.1177/1010428317697578.

21. Liu R, Zeng Y, Zhou CF, Wang Y, Li X, Liu ZQ, Chen XP, Zhang W, Zhou HH. Long noncoding RNA expression signature to predict platinum-based chemotherapeutic sensitivity of ovarian cancer patients. Sci Rep. 2017; 7:18. https://doi.org/10.1038/s41598-017-00050-w.

22. Ge Z, Cheng Z, Yang X, Huo X, Wang N, Wang H, Wang C, Gu D, Zhao F, Yao M, Fan J, Qin W. The long noncoding RNA SchLAH suppresses metastasis of hepatocellular carcinoma through interacting with FUS. Cancer Sci. 2017; 108:653-662. https://doi.org/10.1111/cas.13200.

23. Young TL, Matsuda T, Cepko CL. The noncoding RNA taurine upregulated gene 1 is required for differentiation of the murine retina. Curr Biol. 2005; 15:501-12. https://doi. org/10.1016/j.cub.2005.02.027.

24. Zhang EB, Yin DD, Sun M, Kong R, Liu XH, You LH, Han L, Xia R, Wang KM, Yang JS, De W, Shu YQ, Wang ZX. P53-regulated long non-coding RNA TUG1 affects cell proliferation in human non-small cell lung cancer, partly through epigenetically regulating HOXB7 expression. Cell Death Dis. 2014; 5:e1243. https://doi.org/10.1038/ cddis.2014.201.

25. Sun J, Ding C, Yang Z, Liu T, Zhang X, Zhao C, Wang J. The long non-coding RNA TUG1 indicates a poor prognosis for colorectal cancer and promotes metastasis by affecting epithelial-mesenchymal transition. J Transl Med. 2016; 14:42. https://doi.org/10.1186/s12967-016-0786-z.

26. Jiang L, Wang W, Li G, Sun C, Ren Z, Sheng H, Gao H, Wang C, Yu H. High TUG1 expression is associated with chemotherapy resistance and poor prognosis in esophageal squamous cell carcinoma. Cancer Chemother Pharmacol. 2016; 78:333-9. https://doi.org/10.1007/s00280-016-3066-y.

27. Huang MD, Chen WM, Qi FZ, Sun M, Xu TP, Ma P, Shu YQ. Long non-coding RNA TUG1 is up-regulated in hepatocellular carcinoma and promotes cell growth and apoptosis by epigenetically silencing of KLF2. Mol Cancer. 2015; 14:165. https://doi.org/10.1186/s12943-015-0431-0.

28. Ma B, Li M, Zhang L, Huang M, Lei JB, Fu GH, Liu CX, Lai QW, Chen QQ, Wang YL. Upregulation of long non-coding RNA TUG1 correlates with poor prognosis and disease status in osteosarcoma. Tumour Biol. 2016; 37:4445-55. https://doi.org/10.1007/s13277-015-4301-6.

29. Iliev R, Kleinova R, Juracek J, Dolezel J, Ozanova Z, Fedorko M, Pacik D, Svoboda M, Stanik M, Slaby O. Overexpression of long non-coding RNA TUG1 predicts poor prognosis and promotes cancer cell proliferation and migration in high-grade muscle-invasive bladder cancer. Tumour Biol. 2016; 37:13385-90. https://doi.org/10.1007/ s13277-016-5177-9. 
30. Wang PQ, Wu YX, Zhong XD, Liu B, Qiao G. Prognostic significance of overexpressed long non-coding RNA TUG1 in patients with clear cell renal cell carcinoma. Eur Rev Med Pharmacol Sci. 2017; 21:82-86.

31. Tierney JF, Stewart LA, Ghersi D, Burdett S, Sydes MR. Practical methods for incorporating summary time-to-event data into meta-analysis. Trials. 2007; 8:16. https://doi. org/10.1186/1745-6215-8-16.

32. Lin PC, Huang HD, Chang CC, Chang YS, Yen JC, Lee CC, Chang WH, Liu TC, Chang JG. Long noncoding RNA TUG1 is downregulated in non-small cell lung cancer and can regulate CELF1 on binding to PRC2. BMC Cancer. 2016; 16:583. https://doi.org/10.1186/s12885-016-2569-6.

33. Niu Y, Ma F, Huang W, Fang S, Li M, Wei T, Guo L. Long non-coding RNA TUG1 is involved in cell growth and chemoresistance of small cell lung cancer by regulating LIMK2b via EZH2. Mol Cancer. 2017; 16:5. https://doi. org/10.1186/s12943-016-0575-6.

34. Adelman K, Egan E. Non-coding RNA: More uses for genomic junk. Nature. 2017; 543:183-85. https://doi. org/10.1038/543183a.

35. Gao YL, Zhao ZS, Zhang MY, Han LJ, Dong YJ, Xu B. Long Non-Coding RNA PVT1 Facilitates Cervical Cancer Progression Via Negative Regulating of miR-424. Oncol Res. 2017; 25:1391-1398. https://doi.org/10.3727/096504 $017 \times 14881559833562$.

36. Chandra Gupta S, Nandan Tripathi Y. Potential of long non-coding RNAs in cancer patients: From biomarkers to therapeutic targets. Int J Cancer. 2016; 140:1955-1967. https://doi.org/10.1002/ijc.30546.

37. Li X, Cao Y, Gong X, Li H. Long noncoding RNAs in head and neck cancer. Oncotarget. 2017; 8:10726-40. https://doi. org/10.18632/oncotarget.12960.

38. Chen Y, Huang H, Xu C, Yu C, Li Y. Long Non-Coding RNA Profiling in a Non-Alcoholic Fatty Liver Disease Rodent Model: New Insight into Pathogenesis. Int J Mol Sci. 2017; 18. https://doi.org/10.3390/ijms 18010021.

39. Mortezaei Z, Lanjanian H, Masoudi-Nejad A. Candidate novel long noncoding RNAs, MicroRNAs and putative drugs for Parkinson's disease using a robust and efficient genome-wide association study. Genomics. 2017; 109:158164. https://doi.org/10.1016/j.ygeno.2017.02.004.

40. Tan J, Qiu K, Li M, Liang Y. Double-negative feedback loop between long non-coding RNA TUG1 and miR145 promotes epithelial to mesenchymal transition and radioresistance in human bladder cancer cells. FEBS Lett. 2015; 589:3175-81. https://doi.org/10.1016/j. febslet.2015.08.020.

41. Kuang D, Zhang X, Hua S, Dong W, Li Z. Long noncoding RNA TUG1 regulates ovarian cancer proliferation and metastasis via affecting epithelial-mesenchymal transition. Exp Mol Pathol. 2016; 101:267-73. https://doi. org/10.1016/j.yexmp.2016.09.008.

42. Ma F, Wang SH, Cai Q, Jin LY, Zhou D, Ding J, Quan ZW. Long non-coding RNA TUG1 promotes cell proliferation and metastasis by negatively regulating miR-300 in gallbladder carcinoma. Biomed Pharmacother. 2017; 88:863-69. https://doi.org/10.1016/j.biopha.2017.01.150.

43. Wang Y, Yang T, Zhang Z, Lu M, Zhao W, Zeng X, Zhang W. Long non-coding RNA TUG1 promotes migration and invasion by acting as a ceRNA of miR-335-5p in osteosarcoma cells. Cancer Sci. 2017; 108:859-867. https:// doi.org/10.1111/cas.13201.

44. Cai H, Xue Y, Wang P, Wang Z, Li Z, Hu Y, Li Z, Shang $X$, Liu Y. The long noncoding RNA TUG1 regulates blood-tumor barrier permeability by targeting miR-144. Oncotarget. 2015; 6:19759-79. https://doi.org/10.18632/ oncotarget.4331.

45. Hu Y, Sun X, Mao C, Guo G, Ye S, Xu J, Zou R, Chen J, Wang L, Duan P, Xue X. Upregulation of long noncoding RNA TUG1 promotes cervical cancer cell proliferation and migration. Cancer Med. 2017; 6:471-82. https://doi. org/10.1002/cam4.994.

46. Liu Q, Liu H, Cheng H, Li Y, Li X, Zhu C. Downregulation of long noncoding RNA TUG1 inhibits proliferation and induces apoptosis through the TUG1/miR-142/ZEB2 axis in bladder cancer cells. Onco Targets Ther. 2017; 10:2461-71. https://doi.org/10.2147/ott.s124595. 